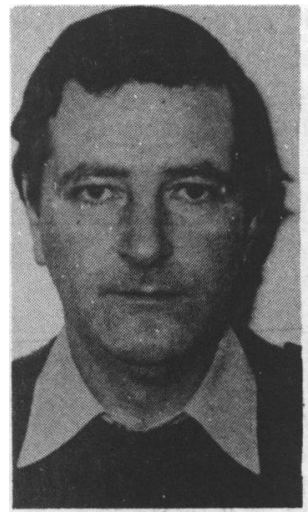

T. A. I. Bouchier-Hayes

\section{NAPROXEN SODIUM AND PIROXICAM IN ACUTE MUSCULO-SKELETAL DISORDERS}

\author{
T. A. I. BOUCHIER-HAYES, FRCGP
}

Senior Medical Officer, The Military Academy, Sandhurst, Camberley, Surrey, GU15 4PH

\begin{abstract}
Of one hundred patients originally entered for this trial eighty-three with acute musculo-skeletal disorders were treated with either naproxen sodium (SYNFLEX, Syntex), $550 \mathrm{mg}$ initially followed by $\mathbf{2 7 5} \mathrm{mg}$ four times daily, or piroxicam (FELDENE, Pfizer), $20 \mathrm{mg}$ twice daily for two days then $\mathbf{2 0} \mathrm{mg}$ once daily. Patients were assessed at admission, on day 4 and on day 8. Pain on passive movement, tenderness, swelling and limitation of function were evaluated and patients also completed a daily self-assessment form. Pain relief was recorded by the patient for 4 hours following the first dose.

No statistically significant differences were detected between the treatment groups for any of the efficacy measurements. Of the eighty-three patients analysed, twenty-four patients withdrew from treatment twenty of whom did not need further analgesia (13 in the naproxen sodium group and 7 in the piroxicam group). Three patients experienced side-effects; all were in the piroxicam group, and one patient withdrew from the study because of epigastric pain.
\end{abstract}

Both naproxen sodium and piroxicam proved effective in the treatment of musculo-skeletal disorders. Naproxen sodium did not give rise to any side-effects.

\section{INTRODUCTION}

Acute traumatic injuries of the musculo-skeletal system are generally treated by mobilisation of the injured part and by administration of an analgesic agent or an antiinflammatory agent with analgesic properties. Inflammation leads to swelling of the tissues and contributes to the loss of function following an acute traumatic injury. Hence, the use of an anti-inflammatory agent with analgesic activity should alleviate pain, reduce swelling and result in the patient regaining the use of the injured structure.

Naproxen sodium (SYNFLEX, Syntex) has a potent analgesic and anti-inflammatory effect and has been shown to be rapidly absorbed (Sevelius et al, 1980). Previous studies of naproxen sodium in this indication

Address for communications:

Medical Reception Station,

Circular Road South,

Colchester,

Essex have shown that it is superior to ibuprofen (Bodiwala, 1982) and to paracetamol/dextropropoxyphene (Abbott et al, 1980) in relieving pain, and similar in efficacy to indomethacin but with fewer sideeffects (Backhouse et al, 1980). Piroxicam (FELDENE, Pfizer), one of the newer non-steroidal anti-inflammatory agents, has also been used successfully in the treatment of musculoskeletal injuries (Hess et al, 1980; Maccagno, 1980). There is, as yet, no direct comparison of these treatments in this indication.

\section{METHOD}

One hundred patients aged 16-70 years, who had 24 hours, were entered originally into this single-blind parallel study. Treatment group allocation was determined randomly and patients received either $550 \mathrm{mg}$ naproxen sodium initially followed by $275 \mathrm{mg}$ four times daily, or $20 \mathrm{mg}$ piroxicam twice daily for two days followed by $20 \mathrm{mg}$ once daily. The total treatment period was seven days. suffered a musculo-skeletal injury within the previous 
Patients with a history of peptic ulcer or disorders of the hepatic, renal or cardiovascular systems were excluded, as were those who had taken analgesics within the previous three days or who were taking highly protein-bound drugs.

Patients were assessed clinically at admission and on days 4 and 8 . The severity of the injury was determined with respect to pain on passive movement, tenderness to firm palpation, swelling and limitation of function, each symptom being graded as none, mild, moderate or severe. A global evaluation of the injury was made, by the physician, at each follow-up visit and this was recorded as cured, improved, same or worse. Throughout the treatment period patients also completed a daily record of their condition in terms of pain severity, degree of use of injured part and improvement of the injury. In addition, the pain relief afforded by the first dose of medication over a 4-hour period was recorded, by the patient, as none, slight, moderate or complete. These data were analysed by using the Mann-Whitney- $U$ test, for between-treatment differences, and the Wilcoxo Wilcoxon signed-rank test, for changes between baseline and end of treatment period.

\section{RESULTS}

Results from 83 patients were analysed. The remaining 17 patients were not included in the analysis because of protocol violations (six in the naproxen sodium group and eight in the piroxicam group), loss to follow-up (one patient in each treatment group) or withdrawal immediately following admission (one patient). This last patient took only one dose before he was found to have haematuria which was taken to be indicative of kidney damage resulting from the injury. Diary cards were available from 77 patients.

The treatment groups were comparable for age, sex and severity of injury (Table I). Injuries were sustained during a sporting or training activity in 70 patients while

\section{TABLE I}

Patient details at entry (excluding the 17 patients who were not analysed as they were pain-free early).

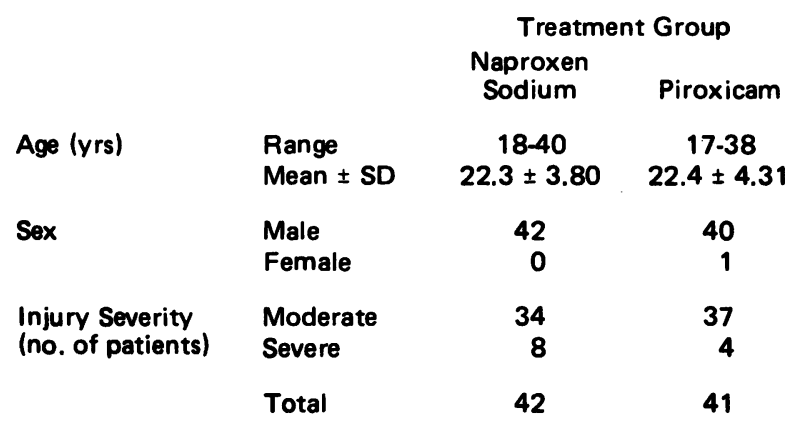

13 patients suffered either a fall or a blow to the site. A $\frac{\mathrm{C}}{\mathrm{c}}$ description of the injuries is given in Table II.

\section{TABLE II}

Injury details

a) Site of injury (no. of patients)

$\begin{array}{lcc}\text { Knee } & \begin{array}{c}\text { Naproxen } \\ \text { Sodium }\end{array} & \text { Piroxicam } \\ \text { Ankle } & 13 & 14 \\ \text { Heel/Achilles tendon } & 11 & 9 \\ \text { Leg/foot } & 7 & 13 \\ \text { Shoulder } & 4 & 5 \\ \text { Groin } & 3 & 0 \\ \text { Neck } & 2 & 0 \\ \text { Ribs } & 1 & 0 \\ & 1 & 0\end{array}$

b) Diagnosis of Injury

$\begin{array}{lrr}\text { Capsule/ligament strain } & 16 & 14 \\ \text { Tendonitis } & 9 & 10 \\ \text { Joint injury } & 5 & 6 \\ \text { Muscle tear/bruising } & 5 & 5 \\ \text { Chondromalacia patella } & 5 & 2 \\ \text { Subcu taneous bruising } & 0 & 2 \\ \text { Injury to periostial junction } & 0 & 2 \\ \text { Torticollis } & 1 & 0 \\ \text { Bursitis/synovitis } & 1 & 0 \\ & 42 & 41\end{array}$

The mean score for each of the four symptoms evaluated was calculated for each assessment visit. Table III shows the mean symptom scores and the numbers of patients at each assessment. Patients were excluded from symptom evaluation either because of non-attendance or because the symptom in question was not' experienced during the study. Both treatment groups showed a statistically significant improvement in symptoms by day 4. There was no statistically significant difference detected between the two groups with respect to any of the symptoms on day 4 or day 8.

No statistically significant difference was detected between the treatment groups for the global assessment. Analysis of the global assessment results took account of patients who had withdrawn by day 8 either because of lack of effect or because pain relief was sufficient such that no further analgesic was needed. Figure 1 illustrates these results.

Analysis of the patient diary-card data did not reveal any statistically significant differences between treatments either in the pain relief afforded by the first dose or in the daily follow-up assessments. 

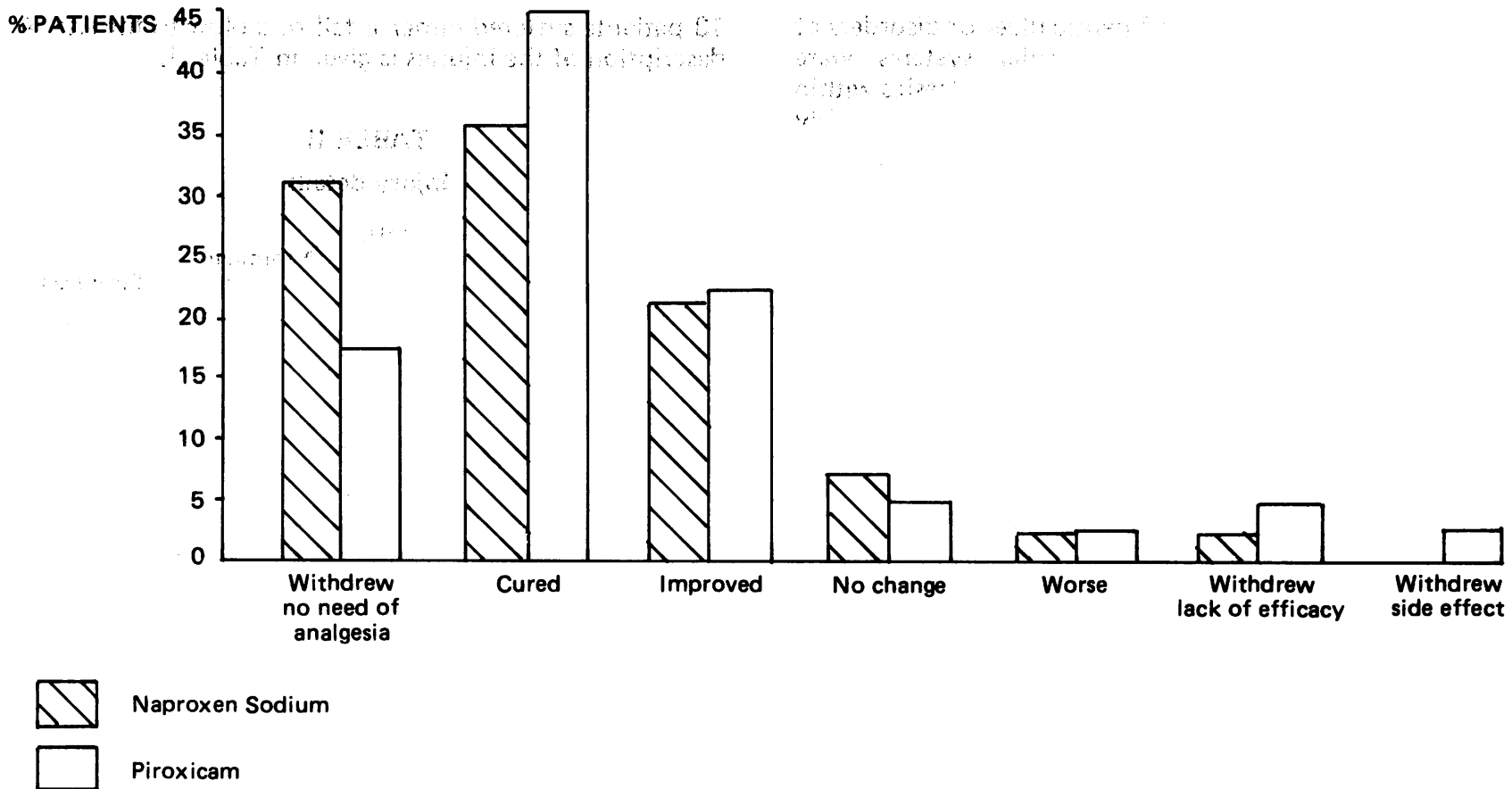

Naproxen Sodium

Piroxicam

Fig. 1: Global assessments and treatment related withdrawals. Day 8.

Twenty-four patients withdrew from the study, twenty of whom did so because they no longer needed analgesia. Thirteen of these patients had been treated with naproxen sodium and seven with piroxicam. Lack of efficacy led to the withdrawal of two patients from the piroxicam group and one from the naproxen sodium group.

One patient in the piroxicam group experienced epigastric pain severe enough to cause withdrawal after four days' treatment. Two more patients suffered sideeffects of tiredness and nausea respectively, during piroxicam treatment.

\section{DISCUSSION}

Eighty-three patients were treated with naproxen sodium or piroxicam for acute musculo-skeletal disorders and, overall, patients showed a marked improvement with treatment.

Almost $25 \%$ of patients had relief of symptoms to such an extent that they did not need to continue with treatment for the full seven days. The majority (13) of these patients had been treated with naproxen sodium. It is of interest that the patients for this study were selected from army personnel, a group of individuals with a very active lifestyle. Any injury, therefore, must be fully cured in order to withstand the strenuous exercise.

\section{TABLE III}

Symptom scores*

Mean \pm SD (Number of Patients)

Naproxen Sodium

$N=42$

Piroxicam
$N=41$

1) Pain

Admission

Day 4

$2.9 \pm 0.57(41)$

$1.8 \pm 0.76(36)$

$1.3 \pm 0.62(27)$

$2.7 \pm 0.61$ (38)

$1.9 \pm 0.72(28)$

$1.3 \pm 0.59(27)$

2) Swelling

Admission

$2.9 \pm 0.82(26)$

$2.7 \pm 0.79(31)$

Day 4

$2.1 \pm 1.00(23)$

$1.4 \pm 0.69$ (19)

$2.0 \pm 0.86(24)$

$1.3 \pm 0.55(24)$

3) Tenderness

Admission

$3.1 \pm 0.47(41)$

Day 4

$2.1 \pm 0.79$ (36)

Day 8

$1.5 \pm 0.79$ (28)

$3.2 \pm 0.50(41)$

$2.1 \pm 0.82(30)$

$1.5 \pm 0.78(30)$

4) Functional Limitation

$\begin{array}{ll}\text { Admission } & 2.9 \pm 0.51(42) \\ \text { Day 4 } & 2.1 \pm 0.82(37) \\ \text { Day } 8 & 1.7 \pm 0.90(28)\end{array}$

$2.9 \pm 0.41(41)$

$2.0 \pm 0.85(30)$

$1.5 \pm 0.73(30)$

${ }^{*}$ none $=1$, mild $=2$, moderate $=3$, severe $=4$.

Since there are several effective treatments available 
for this type of injury, tolerance is an important factor to consider. In this study, naproxen sodium did not produce any side-effects whereas three patients treated with piroxicam developed adverse reactions.
Both naproxen sodium and piroxicam have been shown to be effective in treating acute traumatic injuries. Naproxen sodium was better tolerated and led to the early cure of a greater number of patients.

\section{REFERENCES}

Abbott, C. J. A., Bouchier-Hayes, T. A. I., Hunt, H. A., 1980 "A comparison of the efficacy of naproxen sodium and a paracetamol/dextropropoxyphene combination in the treatment of soft-tissue disorders". Br.J.Sports Med. 14: 213-8.

Backhouse, C. I., Engler, C., English, J. R., 1980 "Naproxen sodium and indomethacin in acute musculo-skeletal disorders". Rheumatol. Rehabil. 19: 113-9.

Bodiwala, G. G., 1982 "Naproxen sodium and ibuprofen in the treatment of acute soft-tissue injuries". Br.J.Clin.Pract. 36: $270-5$.

Hess, H., Rothaar, J., Thiel, W., 1980 "Therapy of acute sports injuries with a new antiarthritic agent, piroxicam". In: $\vec{\infty}$ Proceedings of a Symposium, Malaga. Excerpta Medica: 73-7.

Maccagno, A., 1980 "Piroxicam in the treatment of acute musculoskeletal disorders". In: Proceedings of a Symposium, 을 Malaga. Excerpta Medica: 68-72.

Sevelius, H., Runkel, R., Segre, E. and Bloomfield, S. S., 1980 “Bioavailability of naproxen sodium and its relationship to clinical analgesic effects". Br.J.Clin.Pharmacol. 10: 259-63.

\section{BOOK REVIEW}

Title:

\section{PHYSIOLOGICAL TESTING OF THE ELITE ATHLETE}

Editors:

J. Duncan MacDougall, Howard A. Wenger and Howard J. Green

Publishers:

Canadian Association of Sports Sciences in collaboration with the Sports Medicine Council of Canada Price: $\$ 30$

181 pages

The Canadian physiologists $I$ have met in conferences over the last ten years are enthusiastic, highly capable, individuals. They share the same concern as British physiologists with reference to quality control in testing of elite athletes. In collaboration with the Sports Medicine Council of Canada, the Canadian Association of Sports Sciences, have produced a manual which deals specifically with physiological testing.

The manual devotes a chapter to the evaluation of Strength, Flexibility, Aerobic Power, Anaerobic Power, Body Composition and Anthropometry. Each chapter includes the rationale for testing the physiological component discussed, its relevance to particular sports, the validity and reliability of the testing procedures and guidelines for interpreting the results.

Generally the book is well written, with rationale and methodology clearly defined. In particular, I thought the chapters on Aerobic Power, Anaerobic Power and Kinanthropometry provided essential information with reference to technical laboratory measurement. The Strength chapter was also well written, with perhaps a little too much emphasis on the use of the Cybex machine, which unfortunately is not a feature of British laboratories. Flexibility is always an enigma in the physiological profile of an athlete and the authors, discussing this topic, tended to confirm this without any further enlightenment. The chapter on the Health Status of the Athlete emphasises the need for medical back-up in the testing of elite athletes.

The authors of this manual are knowledgeable scientists with considerable practical experience in the laboratory testing of athletes. This is a useful publication that has highlighted the need for quality control and discussion with reference to athletic testing. It is well referenced and recommended reading for personnel involved in athletic monitoring. 